Prismatika: Jurnal Pendidikan dan Riset Matematika Vol. 3 No. 1 (2020)

p-ISSN: 2654-6140, e-ISSN: 2656-4181

http://ejurnal.budiutomomalang.ac.id/index.php/prismatika

\title{
IDENTIFIKASI BERPIKIR KRITIS STANDAR ANALISIS LEVEL KINERJA NOVICE DENGAN MODEL PEMBELAJARAN ONLINE LEARNING MODEL
}

\author{
Indah Rahayu Panglipur ${ }^{1}$, Lutfiyah ${ }^{2}$ \\ IKIP PGRI Jember ${ }^{1,2}$ \\ indah.ikipjember@gmail.com ${ }^{1}$, azkaluftfimh@gmail.com ${ }^{2}$
}

\begin{abstract}
Abstrak
Kegiatan pembelajaran pada era pandemik dilakukan secara daring atau Online Learning Model (OLM). Tiap mahasiswa yang mengikuti OLM dilatih berpikir kritisnya serta meningkatkan secara rutin penyelesaian suatu permasalahan matematika. Penelitian menggunakan jenis penelitian kualitatif pendekatan deskriptif. Peneliti tertarik untuk mengadakan identifikasi berpikir kritis standar analisis pada level kinerja novice dengan model pembelajaran daring atau Online Learning Model (OLM) pada Perkuliahan Geometri dalam menyelesaikan soal geometri berdasarkan kemampuan berpikir kritis mahasiswa dengan indikator analisis. Subjek diambil berdasarkan nilai tugas pada materi. Subyek dikelompokan dalam 3 kemampuan yaitu kemampuan rendah (Re), kemampuan sedang (Se), dan kemampuan tinggi (Ti). Jumlah subjek sebanyak tiga orang yang diambil dari masing-masing kelompok pada tiap tingkatannya. Pengambilan data dilakukan dengan menggunakan dua instrumen yang saling mendukung yaitu instrument tes dan instrument wawancara. Validasi yang digunakan adalah validasi ahli dan validasi isi. Hasil penelitian menunjukkan bahwa kegiatan pembelajaran daring atau Online Learning Model (OLM) dapat diidentifikasi bahwa subjek dengan kemampuan rendah memenuhi semua indikator pada tahapan analisis. Sedangkan pada kemampuan siswa sedang dan tinggi tidak memenuhi semua indikator. Hal ini sesuai dengan pengertiannya yaitu level kinerja novice adalah level terendah dimana subjek belum mampu menyelesaikan sama sekali masalah yang diberikan.
\end{abstract}

Kata kunci: berpikir kritis, standar analisis, level kinerja novice, Online Learning Model

\begin{abstract}
Learning activities were carried out online or the Online Learning Model (OLM) in the era of the Covid-19 pandemic. Every student who participates in OLM is trained in critical thinking and regularly improves the solving of a mathematical problem. This research used qualitative research with a descriptive approach. Researchers were interested in identifying critical thinking standards of analysis at the Novice Performance Level with the Online Learning Model (OLM) in
\end{abstract}


Geometry Lectures in solving geometric problems based on students' Critical thinking skills with analysis indicators. Subjects were taken based on the assignment score on the material. Subjects were grouped into 3 abilities, namely low ability (Re), medium ability (Se), and high ability (Ti). The number of subjects was three people who were taken from each group at each level. Data were collected using 2 mutually supporting instruments, namely the test instrument and the interview instrument. The validation used was expert validation and content validation. The results showed that online learning activities or the Online Learning Model (OLM) can be identified that subjects with low abilities fulfill all indicators in the analysis stage, while not meeting all indicators for moderate and high student abilities because the Novice performance level is in accordance with its understanding, namely the lowest level where the subject had not been able to solve the given problem at all.

Keywords: critical thinking, standard analysis, novice performance level, Online Learning Model

\section{PENDAHULUAN}

Pembelajaran matematika memerlukan banyak kompetensi yang dilibatkan. Kompetensi yang ada dalam diri sendiri harus diasah dan dikembangkan sesuai dengan potensinya. Kompetensi merupakan kemampuan atau kecakapan seseorang (Putra \& Panglipur, 2019). Pembelajaran matematika sangat berpengaruh terhadap kompetensi diri untuk keberhasilan pembelajaran. Kompetensi diri yang merupakan penggabungan dari pengetahuan, kemampuan, dan keterampilan membentuk karakter diri seseorang (Damayanti \& Dewi, 2013).

Berpikir adalah segala aktivitas mental yang membantu merumuskan atau memecahkan masalah, membuat keputusan atau memenuhi keinginan untuk memahami (Irawan, Susanto, \& Kurnianti, 2015). Tiap orang mempunyai kompetensi yang berbeda-beda sehingga kemampuan berpikir juga pasti berbeda-beda, hal ini dipengaruhi oleh latihan serta pengembangan yang dilakukan. Berpikir kritis adalah suatu bentuk kemampuan berpikir yang harus dimiliki oleh seseorang agar dapat maju dan berkembang. Firdaus, Kailani, Bakar, \& Bakry (2015) mengungkapkan bahwa kemampuan berpikir kritis dibutuhkan di masa mendatang. (Palupi, Sugiarti, \& Kurniati, 2017) mengatakan bahwa sebagian besar siswa belum mampu berpikir kritis. Maulana, Bafadal, \& Untari (2019) menyatakan bahwa kemampuan berpikir kritis dibutuhkan agar sangat dibutuhkan di era teknologi saat ini. Sulistyorini \& Napfiah (2019) memberikan saran kepada peneliti selanjutnya agar pembelajaran matematika sebaiknya memperhatikan aspek berpiki kritis. Ennis (Sari, Susiswo, \& Nusantara, 
2017) mengatakan bahwa berpikir kritis adalah berpikir logis dan reflektif yang terfokus pada cara pengambilan keputusan agar dapat dipercaya dan dilakukan.

Kegiatan pembelajaran pada era pandemik Covid-19 dilakukan secara daring atau Online Learning Model (OLM). Tidak ada pilihan lain untuk kegiatan pembelajaran agar capaian kompetensi berusaha untuk tercapai serta hemat waktu dan tepat untuk keamanan bersama. Pada saat penetapan pelaksanaan OLM tentunya perlu banyak pertimbangan. Salah satu pertimbangan adalah bagaimana nanti hasil dari OLM ini. Padahal dalam pembelajaran matematika membutuhkan waktu tatap muka untuk menjelaskan materi agar dapat dipahami dan diterima dengan baik. Dengan tidak mengurangi tujuan dari hasil yang ingin diperoleh maka perlu ada persiapan yang matang untuk melakukan proses OLM. Pengajar menggunakan beberapa variasi aplikasi yang digunakan dalam OLM diantaranya whatshapp grup, e-learning, dan zoom.

Tiap mahasiswa yang mengikuti OLM dilatih kemampuan berpikirnya agar dapat berpikir kritis pada saat dihadapkan dengan menyelesaikan soal matematika yang memerlukan kemampuan tingkat tinggi yaitu bekerja sesuai dnegan kinerja yang tepat. Pemecahan masalah yang ikut serta melibatkan proses berpikir utamanya dalam menyelesaikan permasalahan geometri, subjek harus dengan sungguh-sungguh dapat mengadopsi berpikir yang imajinatif dan aplikatif. Cara berpikir kritis ini sangat menuntut pengalaman dan ketekunan dalam menyelesaikannnya. Irawan et al. (2015) mengatakan bahwa penilaian kinerja merupakan suatu teknik penilaian yang dipergunakan untuk bisa mengetahui suatu tingkat penguasaan keterampilan terhadap siswa melalui tes penampilan maupun demonstrasi serta praktik kerja nyata. Salah satu level dari kinerja siswa yaitu Novice.

Level kinerja novice adalah level kinerja yang peling rendah dan perlu penanganan yang khusus (Panglipur \& Putra, 2019b). Level ini harus diketahui oleh pengajar karena membutuhkan perbaikan dan tindak lanjut. Pada level ini, subjek tidak mampu berpikir tentang strategi untuk menyelesaikan masalah yang dihadapi terlebih lagi pada akhirnya tidak dapat menyelesaikan, membuktian dengan cara, alasan, serta pemikiran yang logis disesuakan konsep-konsep dasar materinya. Rimbarizki (2017) pengajar perlu mengetahui mahasiswa mana yang berada pada level kinerja ini karena akan menjadi sangat penting diketahui agar informasi tentang ketercapaian hasil pembelajaran dapat diperoleh, tersampaikan dengan baik atau tidak. Maka dapat segera ditemukan dan dicarikan solusi terbaiknya sesuai dengan hasil belajar dengan tidak tatap muka (Anggrawan, 2019). 


\section{METODE PENELITIAN}

Penelitian ini menggunakan jenis penelitian kualitatif menggunakan pendekatan deskriptif (Moleong, 2012). Peneliti tertarik untuk mengadakan identifikasi level kinerja novice melalui kemampuan berpikir kritis (analisis) dengan model pembelajaran daring atau Online Learning Model (OLM) pada perkuliahan Geometri dalam menyelesaikan soal geometri berdasarkan kemampuan berpikir kritis mahasiswa dengan indikator analisis. Dilakukan suatu identifikasi oleh peneliti tentang level kinerja pada mahasiswa dalam berpikir kritis pada subjek yang telah diambil. Subjek diambil berdasarkan nilai tugas pada materi (Anggito, 2018). Subjek dikelompokan dalam tiga kemampuan yaitu kemampuan rendah (Re), kemampuan sedang (Se), dan kemampuan tinggi (Ti). Jumlah subjek sebanyak tiga orang yang diambil dari masing-masing kelompok pada tiap tingkatannya. Pengambilan data dilakukan dengan menggunakan dua instrumen yang saling mendukung yaitu instrumen tes dan instrumen wawancara (Asrori, 2020). Pada instrumen penelitian ini telah divalidasi oleh dua validator ahli dengan hasil revisi telah dilakukan sebanyak satu kali pada bagian kalimat susunannya diperbaiki sehingga menjadi kalimat yang lebih mudah dipahami. Pemberian instrumen tes dilakukan satu kali pada saat akhir setelah dilakukan pembelajaran sedangkan instrumen wawancara dilakukan di luar jam perkuliahan OLM dengan cara melakukan videocall dengan masing-masing instrumen. Selain validasi ahli juga dilakukan validasi isi. Hobri (Panglipur \& Putra, 2019a), dalam penentuan rerata hasil validasi pada indikator menggunakan rumus :

$$
I_{i}=\frac{\sum_{j=1}^{n} V_{j i}}{v}
$$

Keterangan :

$$
\begin{aligned}
V_{j i} & =\text { data nilai dari validator } \mathrm{ke}-j \\
j & =\text { validator } \\
i & =\text { indikator } \\
v & =\text { banyaknya validator }
\end{aligned}
$$

Pada nilai $I_{i}$, kemudian selanjutnya untuk menentukan nilai rerata dari aspek $A_{i}$ menggunakan persamaan:

$$
A_{i}=\frac{\sum_{j=1}^{m} I_{i}}{m}
$$

Keterangan :

$$
\begin{aligned}
& A_{i}=\text { nilai rerata aspek } \\
& I_{i}=\text { rerata nilai untuk aspek ke- } i \\
& i=\text { aspek yang dinilai } \\
& m=\text { banyaknya aspek }
\end{aligned}
$$


Nilai $A_{i}$, selanjutnya menentukan nilai rerata total pada aspek $V_{a}$ menggunakan persamaan berikut :

$$
V_{a}=\frac{\sum_{i=1}^{n} I_{i}}{n}
$$

Keterangan :

$$
\begin{aligned}
& V_{a}=\text { nilai rerata total semua aspek } \\
& I_{i}=\text { rerata nilai untuk aspek ke- } i \\
& i=\text { aspek yang dinilai } \\
& n=\text { banyaknya aspek }
\end{aligned}
$$

Diperoleh $V_{a}$

Kemudian dimasukkan pada kolom yang sesuai pada tabel kriteria berikut.

Tabel 1. Validasi pada Instrumen

\begin{tabular}{cc}
\hline Nilai $\boldsymbol{V}_{\boldsymbol{a}}$ & Tingkat Kevalidan \\
\hline$V_{a}=3$ & Sangat Valid \\
\hline $2,5 \leq V_{a}<3$ & Valid \\
\hline $2 \leq V_{a}<2,5$ & Cukup Valid \\
\hline $1,5 \leq V_{a}<2$ & Kurang Valid \\
\hline $1 \leq V_{a}<1,5$ & Tidak Valid \\
\hline
\end{tabular}

Hasil tes dilihat dari jawaban mahasiswa yang diupload pada $e$ learning yang digunakan mahasiswa. Jawaban tersebut diidentifikasi melalui lembar identifikasi berdasarkan langkah berikutnya dengan mencari indikator pada standar berpikir kritis, untuk kemudian dilakukan pengategorian yang sesuai dalam level kinerja pada pedoman penskoran level kinerja mahasiswa untuk mengetahui pengelompokan kategori level novice. Berikut dilakukan kesimpulan dari rerata total skor yang terdapat di setiap indikator.

Tabel 2. Kategori Level Kinerja Siswa

\begin{tabular}{cc}
\hline Nilai $\boldsymbol{x}$ & Level Siswa \\
\hline$x=4$ & Expert \\
\hline $3 \leq x<4$ & Practitioner \\
\hline $2 \leq x<3$ & Apprentice \\
\hline $1 \leq x<2$ & Novice \\
\hline
\end{tabular}

Pengecakan keabsahan data dilakukan dengan menggunakan triangulasi metode. Triangulasi metode dipilih dalam penelitian ini yaitu tes dan wawancara. Hasil data dari tes yang diberikan didukung dari data yang diperoleh pada saat wawancara sehingga data yang diperoleh konsisten. 
Indah Rahayu Panglipur, Lutfiyah

Identifikasi Berpikir Kritis Standar Analisis Level Kinerja Novice dengan Model

Pembelajaran Online Learning Model

\section{HASIL DAN PEMBAHASAN}

Peneliti mendapatkan data tentang hasil validasi pada instrumen tes dan instrumen wawancara. Adapun hasil validasi kedua instrumen tersebut adalah sebagai berikut.

1. Instrumen tes, nilai $V a$ pada soal tes adalah 2,77 sehingga instrumen tes dikatakan valid sesuai dengan tabel kriteria kategori valid apabila 2,5 $\leq$ $V a<3$.

2. Instrumen wawancara, nilai Va yang diperoleh pada wawancara sebesar 2,65 , sehingga instrumen wawancara dalam kategori valid disesuai dengan tabel kriteria kategori valid apabila 2,5 $\leq V a<3$.

Pengkodean subjek terpilih telah ditetapkan dengan kode $\mathrm{Ti}$ pada mahasiswa berkemampuan tinggi, kode Se pada mahasiswa berkemampuan Sedang, Kode Re pada mahasiswa berkemampuan Rendah. Instrumen tes diberikan melalui e-learning hanya pada ketiga subjek tersebut. Dalam jangka waktu pengerjakan 24 jam harus dikumpulkan. Setelah jawaban subjek terupload maka identifikasi mulai dilakukan oleh peneliti. Pada hari ketiga peneliti mulai melakukan wawancara pada masing-masing subjek melalui videocall aplikasi whatshapp. Dari data hasil tes diperoleh data level novice pada kemampuan berpikir kritis (analisis) adalah pada tabel di bawah ini.

Tabel 3. Data Kemampuan Berfikir Kritis Re

\begin{tabular}{ccll}
\hline Subyek & Standar Kritis & & \multicolumn{1}{c}{ Indikator } \\
\hline $\operatorname{Re}$ & Analisis & a. & $\begin{array}{l}\text { Subyek belum dapat menulis informasi } \\
\text { yang tepat pada permasalahan (Soal) }\end{array}$ \\
& & b. $\begin{array}{l}\text { Subyek telah menulis beberapa konsep, } \\
\text { tetapi masih belum sesuai }\end{array}$ \\
\hline
\end{tabular}

Berdasarkan tabel 3, data hasil kemampuan berpikir siswa kemampuan rendah memperlihatkan bahwa dalam standar kritis, analisis siswa belum dapat menuliskan informasi yang telah ada di soal tes dengan tepat sehingga subjek tidak mampu mengerjakan soal tersebut. Namun subjek telah memahami sebagian permasalahan yang diberikan sesuai hanya pada konsep yang telah diberikan saja. Sehingga belum mampu memahami dengan mengaitkan informasi yang ada dengan konsep. Dengan kondisi subjek sepeti ini, perlu adanya lebih intensif kegiatan pembimbingan oleh pengajar agar subjek tidak mengalami miskonsepsi dan ketertinggalan materi yang cukup jauh. 
Indah Rahayu Panglipur, Lutfiyah

Identifikasi Berpikir Kritis Standar Analisis Level Kinerja Novice dengan Model

Pembelajaran Online Learning Model

Tabel 4. Data Kemampuan Berfikir Kritis Se

\begin{tabular}{|c|c|c|}
\hline Subyek & Standar Kritis & Indikator \\
\hline Se & Analisis & $\begin{array}{l}\text { a. Subyek sudah dapat menulis } \\
\text { beberapa informasi tetapi terdapat } \\
\text { beberapa yang masih belum tepat } \\
\text { b. Subyek sudah dapat menulis konsep } \\
\text { dengan benar }\end{array}$ \\
\hline
\end{tabular}

Tabel 4 menunjukan bahwa kemampuan berpikir subjek dengan kemampuan sedang tampak dalam tahap analisis, subjek sudah dapat menuliskan beberapa informasi walaupun masih terdapat beberapa yang belum tepat. Namun subjek sudah bisa menampilkan/menyajikan informasi yang terdapat pada soal sesuai dengan konsep. Sehingga perlu pembimbingan berlanjut agar dapat meningkatkan kemampuan analisisnya.

Tabel 5. Data Kemampuan Berfikir Kritis Ti

\begin{tabular}{|c|c|c|}
\hline Subyek & Standar Kritis & Indikator \\
\hline $\mathrm{Ti}$ & Analisis & $\begin{array}{l}\text { a. Subyek dapat menuliskan } \\
\text { informasi yang ada dengan tepat } \\
\text { serta benar } \\
\text { b. Subyek telah berhasil menuliskan } \\
\text { konsep dengan tepat serta benar }\end{array}$ \\
\hline
\end{tabular}

Tabel 5 tersebut tentang data kemampuan berpikir pada subjek berkemampuan tinggi, pada tahap analisis subjek mampu menuliskan informasi yang ada secara menyeluruh dari soal tes dengan benar dan tepat. Selain itu subjek telah berhasil menyelesaikan soal tersebut sesuai dengan konsep yang diberikan dengan tepat serta benar. Subjek telah berhasil juga menyajikan penyelesain dengan baik. Dalam tahap seperti ini pengajar tinggal memberikan pengembangan yang menarik untuk meningkatkan daya berpikir kritisnya.

Selanjutnya dilakukan wawancara pada masing-masing subjek. Hasil wawancara yang telah dilakukan dengan videocall mendapatkna hasil berikut ini.

1. Subjek Re

Subjek menyatakan bahwa dalam mengerjakan soal tes belum dapat memahami soal karena memang konsep belum memahami dengan sungguh-sungguh. Pengerjaan soal hanya sebatas dikerjakan apa adanya saja dan tidak memahami sama sekali.

2. Subjek Se

Subjek menyampaikan bahwa memang hanya memahami beberapa 
bagian dari materi/konsep yang telah diajarkan sehingga dalam mengerjakan soal tes juga hanya sebagian saja yang telah dipahami sesuai informasi yang ada. Namun subjek juga menyampaikan bahwa perlu adanya pendalaman kembali konsep yang diberikan oleh pengajar. Subjek masih terlihat berusaha mengerjakan sebentar apa yang dimengerti dan dipahami saja. Perkuliahan dengan zoom merasa sangat penting dilakukan dalam penjelasan materi. Sehingga tidak cukup dengan membaca modul/materi yang dIberikan lewat e-learning saja

3. Subjek Ti

Subjek telah sangat memahami soal dengan baik karena sudah mempelajari konsep/materi yang diberikan oleh pengajar dnegan baik. Mengulang-ulang materi yang diberikan melalui file di e-learning dan mendapat penjelasan yang lebih baik lagi pada saat kegiatan zoom. Sehingga pada saat soal diberikan, subjek dengan cukup mudah menjawab soal yang ada dan dapat menyelesaikan dengan baik dan benar. Subjek menyampaikan memang banyak meluangkan waktu di rumah untuk belajar sendiri, membaca dan latihan soal.

Berdasarkan hasil yang diperoleh dari dua metode tersebut, dilakukan triangulasi metode untuk menguji keabsahan data yang diperoleh dari hasil wawancara dan tes. Kesimpulannya data yang diperoleh sangat sesuai memenuhi masing-masing unsur serta saling menguatkan dan mendukung. Sehingga data bisa digunakan secara keseluruhan setelah dilakukan revisi. Hasil ini sesuai dengan hasil penelitian yang pernah dilakukan sebelumnya (IR panglipur, n.d.) yaitu pada subjek yang berkemampuan rendah perlu banyak pembimbingan dan pendampingan.

\section{KESIMPULAN DAN SARAN}

Kesimpulan dari penelitian ini adalah kegiatan pembelajaran daring atau Online Learning Model (OLM) jika dilihat dari kemampuan berpikir kritis melalui level kinerja novice dapat diidentifikasi bahwa subjek dengan kemampuan rendah memenuhi semua indikator pada tahapan analisis. Sedangkan pada kemampuan siswa sedang dan tinggi tidak memenuhi semua indikator. Hal ini sesuai dengan pengertiannya yaitu level kinerja novice adalah level terendah dimana subjek belum mampu menyelesaikan sama sekali masalah yang diberikan. Saran untuk penelitian selanjutnya dapat diperbanyak ruang lingkup indikator pencapaian kemampuan berpikir kirtis pada level selanjutnya. 


\section{DAFTAR RUJUKAN}

Anggito, A. dan J. S. (2018). Metodologi penelitian kualitatif - Albi Anggito, Johan Setiawan - Google Buku. CV Jejak.

Anggrawan, A. (2019). Analisis Deskriptif Hasil Belajar Pembelajaran Tatap Muka dan Pembelajaran Online Menurut Gaya Belajar Mahasiswa. MATRIK: Jurnal Manajemen, Teknik Informatika Dan Rekayasa Komputer, 18(2). https://doi.org/10.30812/matrik.v18i2.411

Asrori. (2020). Psikologi Pendidikan Pendidikan Pendekatan Multidisipliner. Banyumas: CV Pena Persada.

Damayanti, C., \& Dewi, N. R. (2013). Pengembangan CD Pembelajaran Berbasis Kearifan Lokal Tema Getaran dan Gelombang Untuk Siswa SMP Kelas VIII. USEJ - Unnes Science Education Journal, 2(2). https://doi.org/10.15294/usej.v2i2.2036

Firdaus, F., Kailani, I., Bakar, M. N. Bin, \& Bakry, B. (2015). Developing Critical Thinking Skills of Students in Mathematics Learning. Journal of Education and Learning (EduLearn). https://doi.org/10.11591/edulearn.v9i3.1830

Irawan, D., Susanto, \& Kurnianti, D. (2015). Pelevelan Kinerja Siswa berdasarkan Kemampuan Berpikir Kritis Siswa Kelas VII MTS Negeri Jember dalam Menyelesaikan Soal matematika yang terkit Tema Kopi. Kadikma, 6(3), 57-66.

Maulana, A., Bafadal, I., \& Untari, S. (2019). Model Pembelajaran Value Clarification Technique untuk Meningkatkan Kemampuan Berpikir Kritis dan Keterampilan Sosial Siswa. Jurnal Pendidikan, Teori, Penelitian, Dan Pengembangan, 4(6), 778-784.

Moleong,L, J. (2012). Metodologi Penelitian Kualitatif Edisi Revisi. Bandung: PT Remaja Rosdakarya.

Palupi, D. D., Sugiarti, T., \& Kurniati, D. (2017). Berpikir Kritis dalam Memecahkan Masalah Terbuka Berbasisi Polya Sub Pokok Bahasan Persegi Panjang dan Persegi Siswa Kelas VII-B SMP Negeri 10 Jember. Berpikir Kritis Dalam Memecahkan Masalah Terbuka Berbasis Polya Sub Pokok Bahasa Persegi Panjang Dan Persegi Siswa Kelas VII-B SMP Negeri 10 Jember, 8(3), 162-172.

Panglipur, I. R., \& Putra, E. D. (2019a). Analisis Level Kinerja Expert Melalui Kemampuan Berfikir Kritis Siswa (Interpretasi, Analisis, Evaluasi, Inferansu). Emasians, VIII.

Panglipur, I. R., \& Putra, E. D. (2019b). Identifikasi Level Kinerja Novice Melalui Kemampuan Berpikir Kritis Siswa (Interpretasi, Analisis). Prismatika: Jurnal Pendidikan Dan Riset Matematika, 2(1). https://doi.org/10.33503/prismatika.v2i1.573 
Indah Rahayu Panglipur, Lutfiyah

Identifikasi Berpikir Kritis Standar Analisis Level Kinerja Novice dengan Model

Pembelajaran Online Learning Model

Putra, E. D., \& Panglipur, I. R. (2019). Analisis Level Kinerja Practitioner Melalui Aktivitas Belajar Siswa. Jurnal Pendidikan Matematika (JUDIKA EDUCATION), 2(1). https://doi.org/10.31539/judika.v2i1.700

Rimbarizki, R. (2017). Penerapan Pembelajaran Daring Kombinasi dalam Meningkatkan Motivasi Belajar Perserta Didik Paket C Vokasi di Pusat Kegiatan Belajar Masyarakat (PKBM) Pioneer Karanganyar. J+PLUS UNESA, 6(2).

Sari, M., Susiswo, \& Nusantara, T. (2017). Analisis Kemampuan Berpikir Kritis Siswa Kelas VIII-D Smp Negeri 1 Gambut. Prosiding Seminar Nasional Pendidikan Sains (SNPS), 1(November).

Sulistyorini, Y., \& Napfiah, S. (2019). Persepsi Mahasiswa terhadap 4K dalam Pembelajaran Matematika. Jurnal Matematika Dan Pendidikan Matematika, 4(1), 73-86. 